\title{
PRESENTATION AND TREATMENT OF CAROTID CAVERNOUS ANEURYSMS
}

\author{
Lucas Perez de Vasconcellos', Juan Antônio Castro Flores², \\ José Carlos Esteves Veiga ${ }^{3}$, Mário Luiz Marques Conti ${ }^{4}$, Pedro Shiozawa
}

\begin{abstract}
We analyzed a group of patients with the diagnosis of internal carotid aneurysms in its intracavernous segment, with emphasis in prevalence, clinical features, treatments, evolution and neurological prognosis. Neurological signs and symptoms at initial presentation were registered and compared with final outcome. Patients were divided into two stratified groups, one with 19 patients which underwent interventionist treatment, and another with 21 patients who were conservatively treated. The present study demonstrated that intervention is significantly correlated with a better prognosis considering evolution of pain symptoms secondary to neurovascular compression ( $p=0,002)$. Regarding neurological deficits, an interventionist approach was also significantly correlated with better outcome in comparison with initial presentation $(p=0,008)$. These results indicate that interventionist treatment determines improvement or resolution of pain symptoms in comparison with patients conservatively treated, as well as stabilization or partial improvement of neuroophthalmological deficits.
\end{abstract}

KEY WORDS: carotid cavernous aneurysm, clinical treatment, interventionist treatment, prognosis.

\begin{abstract}
Apresentação e tratamento dos aneurismas intracavernosos
Resumo - Analisamos um grupo de pacientes com diagnóstico de aneurismas da artéria carótida interna, em sua porção intracavernosa, estudando-se: prevalência, apresentação clínica, formas de tratamento, evolução e prognóstico neurológico. Os sintomas e sinais neurológicos da apresentação foram registrados e comparados ao término do acompanhamento, com um grupo de 21 aneurismas submetidos a tratamento conservador $\mathrm{e}$ outro com 19 a tratamento intervencionista. $O$ estudo demonstrou que a intervenção está relacionada a um melhor prognóstico, quanto à evolução do quadro álgico secundário à compressão neurovascular $(p=0,002)$. Em relação ao déficit neurológico, a abordagem intervencionista pôde ser associada com uma melhora do quadro inicial $(p=0,008)$. Estes resultados indicam que o tratamento intervencionista proporcionou melhora ou resolução do sintoma dor em comparação ao grupo de pacientes com tratamento conservador, além de levar a uma estabilização ou melhora parcial dos déficits neuro-oftalmológicos.
\end{abstract}

PALAVRAS-CHAVE: aneurisma intracavernoso, tratamento clínico, tratamento intervencionista, prognóstico.

Internal carotid aneurysms in its intracavernous segment represent approximately $3-5 \%$ of all intracranial aneurysms ${ }^{1}$ and $15 \%$ of those originated in the internal carotid $^{2}$. Carotid cavernous aneurysms (CCA) can arise from any segment of cavernous carotid artery (Fig 1), but most commonly are originated in the horizontal segment, being projected forwardly and laterally, with the superior orbitary fissure and below the anterior clinoid process ${ }^{3}$. This preferential site is related with the three most common branches of this segment (McConnell's capsular artery, inferolateral trunk and meningohypofisary trunk $)^{4}$. This sug- gests that the hemodynamic stress verified in these bifurcations can contribute to the aneurysms ${ }^{\prime}$ genesis ${ }^{3,5}$. Other aneurysmatic sites within the intracavernous segment are also common, what can interrogate the existence of other pathogenic mechanisms as atherosclerosis and dissection, spontaneous or traumatic ${ }^{6}$.

CCA morbidity and mortality indices are low ${ }^{7-10}$, however, pain and neuro-ophthalmologic deficits due to neurovascular compression are frequent, what highlights the possibility of surgical treatment ${ }^{6,11}$. The vast majority of intracranial intradural aneurysms can be micro-surgically

Santa Casa Medical School, Discipline of Neurosurgery, São Paulo SP, Brazil: 'Resident of Neurosurgery; ${ }^{2}$ Assistant Physician; ${ }^{3}$ Adjunct Professor and Head of Neurosurgery; ${ }^{4}$ Assistant Physician and Head of Interventionist Neuroradiology Service; ${ }^{5}$ Medical Student.

Received 26 September 2007, received in final form 6 February 2008. Accepted 23 February 2008.

Dr. Lucas Perez de Vasconcellos - Rua Desembargador Joaquim Barbosa de Almeida 368 -05463-010 São Paulo SP - Brasil. E-mail: lucasvasconcellos@ hotmail.com 
treated, commonly through aneurysmatic isolation without vascular occlusion, while CCA, when operated, frequently are through occlusion of ipsilateral internal carotid artery (ICA), with cerebral ischemia and amaurosis risks ${ }^{12-14}$. ICA endovascular occlusion has apparently a better outcome than ICA ligature ${ }^{13,15,16}$, although there is still much controversy around this matter, with authors in favor of surgical treatment of CCA patients with or without symptoms ${ }^{15,17}$, and others which are contrary to surgical treatment in both groups ${ }^{18}$. The reason for this controversy is in the lack of data on the natural history and long term outcome of CCA surgical patients 16,19,20. $^{10}$.

The following study has the objective to determine the long-term neurological outcome of the patients diagnosed with carotid cavernous aneurysms in our Center, treated conservatively or surgically, with emphasis in prevalence, clinical presentation, therapeutical strategies, outcome and neurological prognostic.

\section{METHOD}

After approval from the Institutional Review Commission, the Discipline of Neurosurgery of Santa Casa Medical School of São Paulo studied patients with the diagnostic of cerebral aneurysms in the period between January 1989 and April 2007.

These patients were analyzed regarding genre, age, site and number of aneurysms, being selected for a second phase of the study those with CCA between (C3) lacerus segment and (C5) clinoid segment of ICA ${ }^{4}$. There were excluded from the study patients that presented aneurysms with partial or total intradural or subarachnoid colon, displasic aneurysms (beyond segment C4 of ICA) and traumatic or infectious aneurysms. All the selected patients were submitted to a full neurological exam and underwent radiological study with contrasted cranial computed tomography scan (CT), complete cerebral angiography (CAG) with and without subtraction and magnetic resonance imaging scan (MRI) with slices from the paraselar region after 90's (Fig 2).

The data from patients ' files were completed afterwards during medical appointments. The following items were verified: age of diagnostic, age during treatment, genre, ethnic, morbid antecedents, site and size of aneurysm, presence of other aneurysms, neurological and visual signs and symptoms, therapeutic options and complications after treatment. The patients were divided into two groups, one which underwent conservative treatment and other, interventionist treatment. It was considered to be interventionist treatment endovascular approach with coils, stent and ICA occlusion with ballon as well as ICA ligature with or without external carotid by-pass to media cerebral artery or ICA trapping.

As to measure, according to Liskey et $\mathrm{al}^{6}$, pain symptoms and neurological deficits, the pain was graduated in severe, moderate, weak or absent, while neurological deficits were classified as severe, in the presence of cavernous sinus syndrome including trigeminal neuropathies; moderated, if there were complete

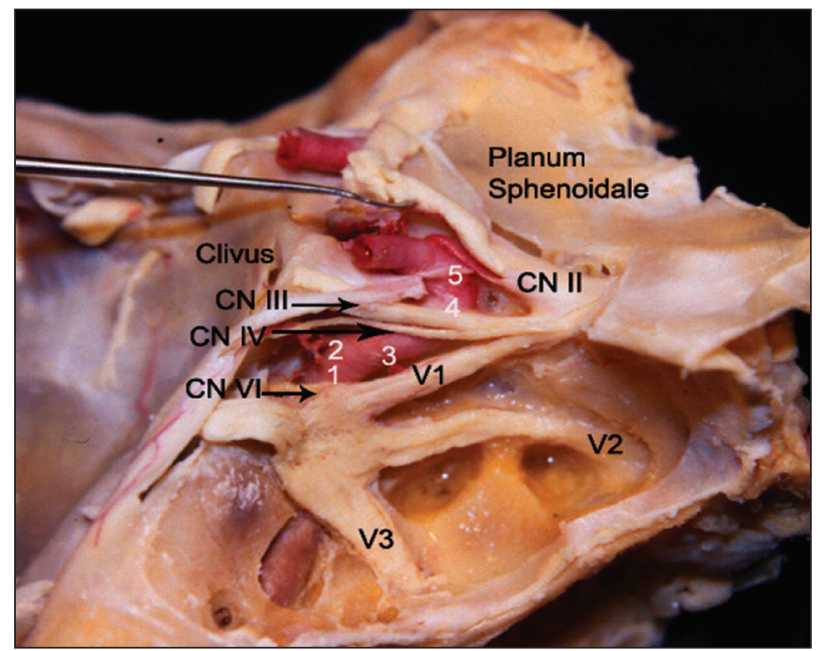

Fig 1. Cavernous sinus dissection, demonstrating cranial nerves: IIIII-IV-VI-V2-V3-VI; 1, the posterior vertical segment; 2 , the posterior bend; 3, the horizontal segment; 4, the anterior bend; 5, the anterior vertical segment (By Castro JAF, MD).
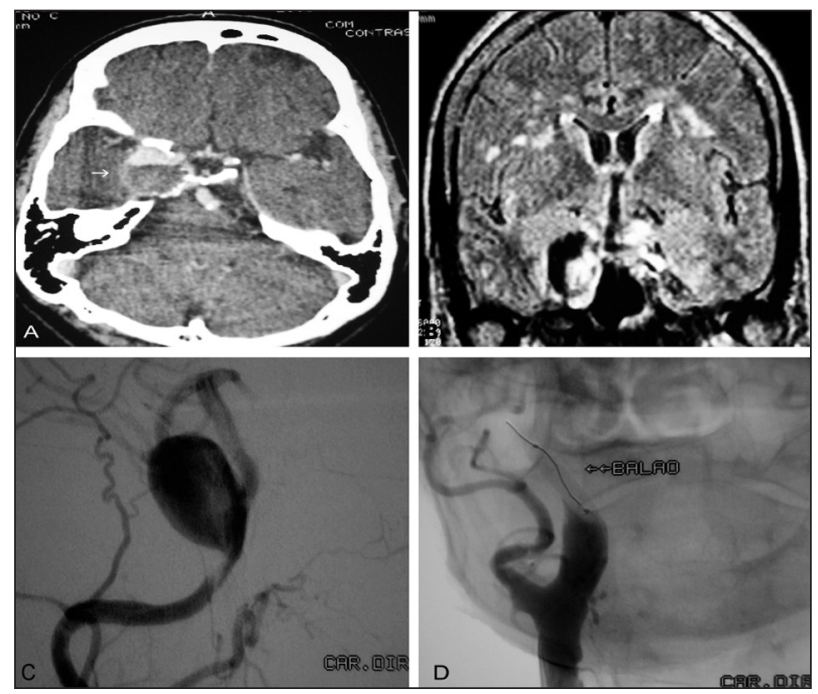

Fig 2. (A) CT scan showing giant aneurysm of Right ICA, partially occluded by thrombosis in a female 67 year old patient with headache, retro bulbar pain, full III cranial nerve, Right IV, VI, V1 and V2. (B) MRI scan showing important dilatation of a partially occluded aneurysm with thromboses. (C) Angiography of the same patient. (D) Right ICA occlusion with balloon.

involvement of III, IV and VI cranial nerves; weak, if there were deficits in one or two cranial nerves; and absent.

Each patient was classified taking into account his initial and final presentation during overcome: 0 , absence of symptoms; 1 , weak pain or neurological deficit; 2, moderate pain or neurological deficit; 3 , severe pain or neurological deficit.

Statistical analyses were performed using the $[\mathrm{chi}]^{2}$ test with analysis of covariance and multinomial logistic regression. We demonstrated with statistical significance the impact of treatment regarding pain and neurological deficits, considering values of $p<0,05$ for bicaudal tests. 


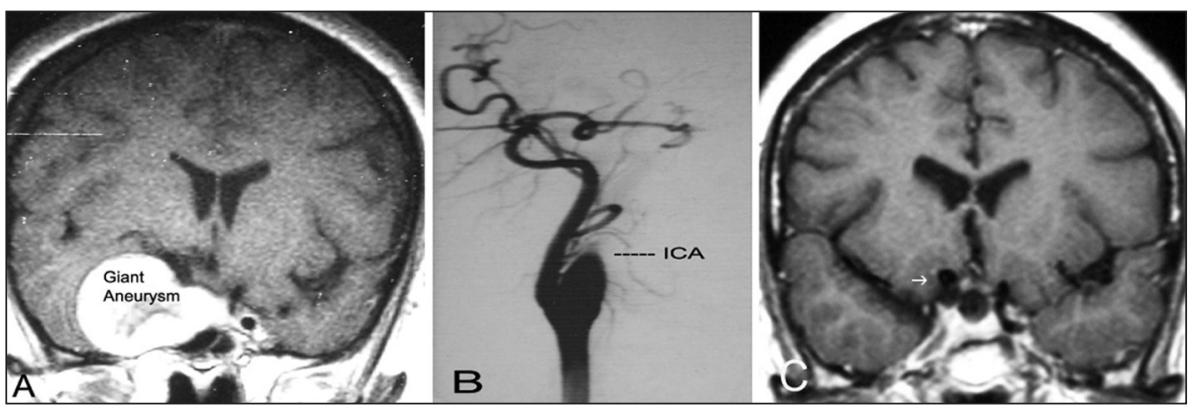

Fig 3. (A) MRI scan presenting a coronal slice in which can be seen giant aneurysm in right ICA in a 57 year old patient with headache and right III, IV and VI. (B) After months, presented complete remission of headache with angiography showing Right ICA spontaneous thrombosis. (C) Axial slice from a MRI scan showing remission of aneurysmatic dilatation of right ICA after a 10 year follow up.

\section{RESULTS}

There were identified 711 patients, with average age of 41 years ( $41 \pm 11.3), 73 \%$ females and $27 \%$ males, with a total of 802 aneurysms which underwent either conservative or interventionist treatment by the Neurosurgery Discipline. Of those patients, 35 presented with CCA with a total of 40 aneurysms, $5 \%$ of all intracranial aneurysms. Thirty-two patients (91.4\%) were alive until the end of the study, while $3(8.6 \%)$ were not. None of the obits was related to the CCA or its treatment, two were due to surgical complications of other intracranial aneurysms and one was due to undetermined factors.

Thirty-two patients (91.4\%) were females and three, male $(8.6 \%)$. Average age by the time of diagnostic was 48.4 years ( $48.4 \pm 57.1$ months), with a median of 47 years (total variation between 19 and 67 years) and an average time of follow of 60.5 months. There was a higher prevalence of white middle-age females, being arterial hypertension the only consistent systemic alteration found, presented in $48,5 \%$ of the patients studied. Thirty from the 35 patients had unilateral CCA $(85.7 \%)$, from a total of 40 aneurisms, $50 \%$ of the aneurysms were from the right side. Fifty percent were classified as giant aneurysms $(>2.5$ $\mathrm{cm})$ as shown in Figures 2 and 3 and thirteen were classified as large $(1.0-2.5 \mathrm{~cm})$. Seven patients $(21.2 \%)$ had aneurysms in other sites.

Thirty-three patients (94.2\%) had symptoms due to CCAs (Table 1). The most frequent was headache, presented in 33 patients (94\%), followed by diplopic vision due to compromised VI cranial nerve (82.8\%). Sequentially, there
Table 1. Incidence of symptoms in the presentation of patients with intracavernous aneurysms.

\begin{tabular}{lcc}
\hline Symptom & Surgery $(\mathrm{n}=19) \%$ & Conservative $(\mathrm{n}=21) \%$ \\
\hline Diplopy $^{\mathrm{a}}$ & $16(84.2 \%)$ & $18(85.7 \%)$ \\
Pain $^{\mathrm{b}}$ & $19(100 \%)$ & $9(42.8 \%)$ \\
Incidental & 0 & $2(9.5 \%)$ \\
Visual deficit & $5(26.3 \%)$ & $4(19 \%)$ \\
\hline
\end{tabular}

${ }^{a} p=0.008 ;{ }^{b} p=0.002$.

was retro bulbar pain in 18 patients (54.5\%), deficit in visual accuracy in 9 patients (17.8\%), photophobia in two cases and facial pain in one case (Table 1). All cases of ICA aneurysms with incidental diagnostic were clinically treated and observed without surgical intervention.

The clinical sign of highest prevalence was ophthalmic paresis, observed in 33 patients (94.2\%), being multiple in 23 cases (69.6\%) and isolated in 10 patients (30.3\%). The most affected cranial nerve was the abducent (90\%). Other signs were sensorial trigeminal neuropathy in $11 \mathrm{pa}-$ tients (31.4\%), followed by three cases of ischemic cerebral vascular accident (ICVA) and two of epistaxis.

Nineteen aneurysms (47.5\%) underwent surgical treatment (Table 2). The most frequent surgery was ICA occlusion (11 cases). Ten of these patients were submitted to carotid occlusion test with balloon (Fig 2) and one with Silverstone clamp. Eight patients (23.5\%) underwent surgery with ICA ligature after cervicotomy (Fig 2). Three patients were treated with detachable balloon allocated by endovascular technique after collateral circulation test. Four

Table 2. Distribution of terapeutical strategies of patients with intracavernous aneurysms.

\begin{tabular}{lcccccccc}
\hline & N aneurisms & Clinical & Surgical & ICA ligature & ICA balloon & Embolization & By pass & Trapping \\
\hline RICA & 20 & 10 & 10 & 6 & 1 & 1 & 1 & 1 \\
LICA & 20 & 11 & 9 & 2 & 2 & 4 & 5 & 1 \\
Total & 40 & 21 & 19 & 8 & 3 & 5 & 1 & 2 \\
\hline
\end{tabular}

LICA, left internal carotid artery; RICA, right internal carotid artery. 
patients were treated with simple aneurysmatic embolization and one with embolization associated with ICA stent. Two cases were submitted to ICA trapping and one patient was treated with high flow by-pass (Safen vein in external carotid artery - media cerebral artery).

Twenty-one aneurysms (52.5\%) had conservative treatment (Table 2), 10 were giant, there were five cases of spontaneous thrombosis: one of the aneurysm and four (20\%) of ICA (Fig 3). In these five cases there was important remission of the pain symptoms.

Among the 19 patients that underwent surgical treatment, seven (36.8\%) had surgical complications. Two patients had transitory motor deficit, manifested as a transitory ischemic attack. Considering permanent complications, one patient presented ophthalmic paresis associated with amaurosis and another patient had a cerebrovascular accident. As late complications there was a case of carotid-cavernous fistula and two cases of collateral cavernous aneurysms.

In the group of patients surgically treated, $85 \%$ had improvement of pain and $15 \%$ did not present alterations in initial pain symptoms. Regarding neurological deficits, there was improvement of symptoms in $70 \%$ of patients while $30 \%$ were stable.

Patients treated conservatively presented in $16.7 \%$ of the cases improvement of pain while $58.3 \%$ were stable and $25 \%$ had intensification of the initial pain symptoms. Regarding neurological deficits, patients treated clinically did not have improvement of symptoms, $66.7 \%$ were stable and $33.3 \%$ presented intensification of deficits.

Analyzing all patients without therapeutical strategy distinction, there was improvement of pain symptoms in $56.7 \%$ of the cases, stability in $33.3 \%$ and increase in pain in $10 \%$. Considering neurological deficits, there was improvement of symptoms in $36.7 \%$ of the patients, stability in $50 \%$ and decrease of the deficit in $13.3 \%$.

Statistical analysis was performed through $\left[\mathrm{chi}^{2}\right]$ test with analysis of covariance and multinomial logistic regression, which demonstrated that surgical intervention is related with better neurological prognostic in comparison with the group treated conservatively; i.e., resolution of pain scenario independently of initial intensity $(p=0.002)$ and stabilization or resolution of neurological deficits, independently of initial intensity of clinical features used for classification ( $p=0.008$ ).

Regarding aneurysms ${ }^{`}$ size (large or giant) there was no statistically significant relation with neurological deficit outcome $(p=0.836)$ or initial pain symptoms $(p=0.909)$.

With the purpose of verifying the impact of age on the prognostic of both, pain and neurological symptoms, we divided the population studied into two groups using as limit value between the groups the mediana of ages.
Group A was composed of individuals with less then 55 years of age and group $B$ of individuals with 55 years old or more. Comparing both groups, we observed that age could not be statistically related to neither pain nor neurological symptoms (respectively, $\mathrm{p}=0.714$ and $\mathrm{p}=0.916$ ).

\section{DISCUSSION}

Using Pubmed data base there were identified only three studies with large series of CCAs, including one with natural history of 79 aneurysms with a follow up of 10 years ${ }^{14}$ and other two studies which emphasized patients neuro-ophtalmological prognostic: one with 40 CCAs for 30 years $^{19}$ and other, a multi-centric study with 206 aneurysm with a follow up of 16 years $^{20}$. In the present study, we observed the clinical outcome for both conservative and interventionist therapeutical strategies, with emphasis on neurological prognosis, including statistical analysis of all patients with intracranial aneurysms in a 19-year period of segment, all treated and followed in our institution. CCAs are more frequent in white females, with the beginning of symptoms around $5^{\text {th }}$ and $6^{\text {th }}$ decades ${ }^{6}$. Similarly, systemic arterial hypertension is a risk factor for the development of intracranial aneurysms, this disease was present in 17 of the 35 patients when the aneurysms were first detected, independently of previous history of hypertension.

The presence of bilateral cavernous aneurysms in 5 patients, was common and in accordance with data from previous studies ${ }^{4,6,14,19}$. Seven patients had intracranial aneurysms in other sites, suggesting that a degenerative process secondary to a genetic factor of fragility in the vascular wall should be present.

Rarely do CCAs suffer rupture and subarachnoid hemorrhage by the time of diagnostic, due to the fact that cavernous sinus are composed by dural slices, which lay over the body of sphenoid and are, infrequently, projected towards the subarachnoid space ${ }^{4,11}$.

Two patients were asymptomatic when the diagnostic was made, and the presence of CCAs was only verified after angiography for investigation of other brain aneurysms. In the presence of rupture, commonly, there are carotid-cavernous fistulas or epistaxis ${ }^{8,19,21}$ with low morbidity and mortality rates if surgical treatment is adopted. In our study two patients had epistaxis when CCAs were diagnosed and two who underwent interventionist treatment presented later carotid-cavernous fistulas, with satisfactory evolution: both patients with epistaxis were submitted to ICA ligature and one patient with fistula was submitted to endovascular treatment.

CCAs frequently determine symptoms as consequence of neurovascular compression, being the most prevalent in the present study, diplopia. This symptom follows VI 
cranial nerve lesions due to its position within cavernous sinus, as demonstrated in Image ${ }^{4,10}$. The association with other nerves (III, IV, V1 and V2), located in the lateral wall of cavernous sinus characterizes the complete cavernous sinus syndrome $e^{9,0,19,20}$.

Considering the group of patients submitted to conservative treatment, it could be verified a relapsing and fluctuating course of pain symptoms and a progressive impairment of cranial nerves ${ }^{-}$function, determining a poor neurological outcome.

Patients submitted to interventionist treatment, i.e., endovascular treatment with coils, stent and ICA occlusion with balloon, as well as simple ICA ligature, ICA ligature associated with external carotid to media cerebral artery by-pass and ICA trapping, could be compared and included in a same group for having as final result of surgical strategy, aneurysmatic or carotid exclusion from circulation.

The interventionist therapy altered significantly the outcome of neurological deficits: the surgically treated group presented improvement of symptoms in $70 \%$ of the cases $(p=0.008)$, avoiding in all cases the progression of installed neurological deficits.

The pain scenario, determined by headache, hemi facial pain and retro bulbar pain, was improved or extinguished in $100 \%$ of the patients submitted to interventionist treatment $(p=0.002)$.

Brain infarcts occurred in three of nineteen patients that underwent interventionist treatment, two were transitory in consequence of transitory ischemic attach and one after ischemic cerebral vascular accident ${ }^{11}$. Complication rates in our study are comparable to those verified in literature ${ }^{13,19,21}$

In conclusion, cavernous carotid artery aneurysms present a satisfactory long-term neurological outcome with low complication rates if submitted to interventionist treatment, what determines improvement or resolution of pain symptoms in comparison with patients conservatively treated, as well as stabilization or partial improvement of neuro-ophthalmological deficits.

\section{REFERENCES}

1. Bars HW, Blackwood W, Meadows SP. Intracavernous carotid aneurysms. A clinical-pathological report. Brain 1971;94:607-622.

2. Bavinzski G, Killer M, Ferraz-Leite H, et al. Endovascular therapy of idiopathic cavernous aneurysms over 11 years. Am J Neuroradiol 1998;19:559-565.

3. Derdeyn CP, Cross DT, Moran CJ, et al. Postprocedure ischemic events after treatment of intracranial aneurysms with Guglielmi detachable coils. J Neurosurg 2002;96:837-843.

4. German WJ, Black SP. Cervical ligation for internal carotid aneurysms: an extended follow-up. J Neurosurg 1965;23:572-577.

5. Goddard AJ, Annesley-Williams D, Gholkar A. Endovascular management of unruptured intracranial aneurysms: does outcome justify treatment? J Neurol Neurosurg Psychiatry 2002;72:485-490.

6. Goldenberg-Cohen N, Curry C, Miller NR, et al. Long term visual and neurological prognosis in patients with treated and untreated cavernous sinus aneurysms. J Neurosurg 2004;75:863-867.

7. Higashida RT, Halbach VV, Dowd C, et al. Endovascular detachable balloon embolization therapy of cavernous carotid artery aneurysms: results in 87 cases. J Neurosurg 1990;72:857-863.

8. Inagawa T. Follow-up study of unrupted aneurysms arising from C3 and C4 segments of the internal carotid artery. Surg Neurol 1991;36:99-105.

9. Inoue T, Rhoton AL Jr, Theele D, et al. Surgical approaches to cavernous sinus: a microsurgical study. Neurosurgery 1990;26:903-932.

10. Johnston SC, Wilson CB, Halbach VV, et al. Endovascular and surgical treatment of unruptured cerebral aneurysms: comparison of risks. Ann Neurol 2000;48:11-19.

11. Kupersmith MJ, Berenstein A, Choi IS, et al. Percutaneous transvascular treatment of giant carotid aneurysms: neuro-ophthalmologic findings. Neurology 1984;34:328-335.

12. Kupersmith MJ, Hurst R, Berenstein A, et al. The benign course of cavernous carotid artery aneurysms. J Neurosurg 1992;77:690-693.

13. Kupersmith MJ, Stiebel-Kalish H, Huna-Baron R, et al. Cavernous carotid aneurysms rarely cause subarachnoid hemorrhage or major neurologic morbidity. J Stroke Cerberovasc Dis 2002;11:9-14.

14. Kupersmith MJ. Aneurysms involving the motor and sensory visual pathways. In: Neuro-Vascular Neuro-Ophthalmology. Heidelberg: Springer-Verlag, 1993:254-261.

15. Linskey ME, Sekhar LN, Hirsch WL Jr, et al: Aneurysms of the intracavernous carotid artery: natural history and indications for treatment. Neurosurgery 1990;26:933-937.

16. Locksley HB. Natural history of subarachnoid hemorrhage, intracranial aneurysms and arteriovenous malformations. J Neurosurg 1966;25:321-368.

17. Miller NR. Carotid-cavernous sinus fistulas. In: Miller NR, Newman NJ (Eds). Welsh \& Hoyt's clinical neuro-ophthalmology. Baltimore: Williams and Wilkins, 1997:3263-3322.

18. Newman SA. Aneurysms. In Miller NR, Newman NJ (Eds). Walsh \& Hoyt's clinical neuro-ophthalmology. Baltimore: Williams and Wilkins, 1997:2975-3261.

19. Stiebel-Kalish H, Kalish Y, et al. Presentation, natural history, and management of carotid cavernous aneurysms. Neurosurgery 2005;57:850-857.

20. van der Schaaf EH, Buskens E, Rinkel GJ. Endovascular treatment of aneurysms in the cavernous sinus: a systematic review on balloon occlusion of the parent vessel and embolization with coils. Stroke 2002;33: 313-318.

21. Yasuda A, Rhoton AL Jr, de Oliveira E, et al. Microsurgical anatomy and approaches to the cavernous sinus. J Neurosurg 2005;56:4-27. 